\title{
Obesity as a risk and severity factor in rheumatic diseases (autoimmune chronic inflammatory diseases)
}

\section{Elisa Gremese, Barbara Tolusso, Maria Rita Gigante and Gianfranco Ferraccioli*}

Division of Rheumatology, Institute of Rheumatology and Affine Sciences, Catholic University of the Sacred Heart, Rome, Italy

\section{Edited by:}

Giamila Fantuzzi, University of Illinois at Chicago, USA

\section{Reviewed by:}

Gaurav K. Gupta, Harvard Medical School, USA

Cem Gabay, University Hospitals of Geneva, Switzerland

*Correspondence:

Gianfranco Ferraccioli, Division of Rheumatology, Institute of

Rheumatology and Affine Sciences, Catholic University of the Sacred

Heart, Via Moscati 31, Rome 00168, Italy

e-mail:gf.ferraccioli@rm.unicatt.it
The growing body of evidence recognizing the adipose tissue (AT) as an active endocrine organ secreting bioactive mediators involved in metabolic and inflammatory disorders, together with the global epidemic of overweight and obesity, rise obesity as a hot topic of current research. The chronic state of low-grade inflammation present in the obese condition and the multiple pleiotropic effects of adipokines on the immune system has been implicated in the pathogenesis of several inflammatory conditions including rheumatic autoimmune and inflammatory diseases. We will discuss the main relevant evidences on the role of the AT on immune and inflammatory networks and the more recent evidences regarding the effects of obesity on the incidence and outcomes of the major autoimmune chronic inflammatory diseases.

Keywords: rheumatic diseases, body mass index, obesity, adipokines, inflammation, rheumatoid arthritis

\section{INTRODUCTION}

In the last few years, the interest and research in the field of obesity have esponentially risen, due to its increased prevalence and to the burden of the obesity-related diseases (1).

Moreover, white adipose tissue (WAT) has emerged as an active endocrine organ, playing a role not only on metabolism but also on immune and inflammatory processes by releasing a plethora of adipocytokines and pro-inflammatory mediators, among which TNF- $\alpha$, IL-6, adiponectin, leptin, resistin, visfatin, and C-reactive protein (2).

The inflammatory role of the adipose tissue (AT), together with the rise in incidence of autoimmune diseases, has growing a huge interest in the relationship between obesity and chronic inflammatory diseases.

Obesity in turn predisposes to metabolic and cardiovascular diseases, and it is becoming clear that the dietary habits in Western societies ("too much," "too fatty," "too salty") and a high body mass index (BMI) constitute risk factors for autoimmune diseases (3).

\section{DEFINITION AND PREVALENCE OF OBESITY IN RHEUMATIC DISEASES}

Overweight and obesity are defined by the World Health Organization (WHO) as abnormal or excessive fat accumulation that presents a risk to health (4). BMI was developed as a clinically measurable approximation for body fat percentage and according to the National Institute of Health (NIH) classification, BMI was categorized into three classes, as a $\mathrm{BMI}<25 \mathrm{Kg} / \mathrm{m}^{2}$, identifying normal-weight status, BMI $25-30 \mathrm{Kg} / \mathrm{m}^{2}$, identifying overweight and $\mathrm{BMI}>30 \mathrm{Kg} / \mathrm{m}^{2}$, identifying obese status (5).

Body mass index is recognized as a valid measure of absolute fat mass adjusted for height, yet the use of BMI may present some limits. First, the abdominal fat distribution has been suggested being more stringently associated with cardiovascular risk and with AT effects, so anthropometric measures such as waist circumference has been shown to better reflect central or abdominal adiposity than BMI. Waist circumference is accepted as a clinical measure of abdominal obesity and has been proposed as substantial indicator of health risk and as a criteria for the metabolic syndrome (6). Moreover, the accuracy of BMI in estimating the amount of fat mass may vary according to age, as in the older age the lean body mass tends to decrease in favor to adipose mass, to gender, as female had higher proportion of AT, and under some inflammatory disease condition that may alter the body mass composition, like rheumatoid arthritis (RA).

Indeed, methods allowing for the characterization of body fat proportion (e.g., dual energy $x$-RAY absorpsiometry-DXA, bioelectrical impedence) demonstrated that RA patients have more body fat for a given BMI than healthy controls; moreover, male RA patients had more visceral fat and female more subcutaneous fat compared with controls with similar BMI and waist circumference, so lower BMI cut-offs has been proposed to improve the predictive value of this indicator in RA $(7,8)$.

However, at present BMI still remains a valid and easily evaluable surrogate to estimate total body fat mass in clinical evaluation (9).

To date, the prevalence of obesity and overweight in autoimmune chronic inflammatory diseases (ACIDs) are not exhaustively reported and may widely varies depending on the populations considered, the type of disease and the disease duration at the time of evaluation, because the disease and therapy can modify the body weight and composition. Overall, the prevalence of obesity in many rheumatic diseases seems to be similar to slightly higher than the general population, with the exception of Psoriatic Arthritis (PsA). Figure 1 illustrates the distribution of normal weight, overweight, and obese subjects in different cohorts of patients with the most representative inflammatory, autoimmune, and vascular 


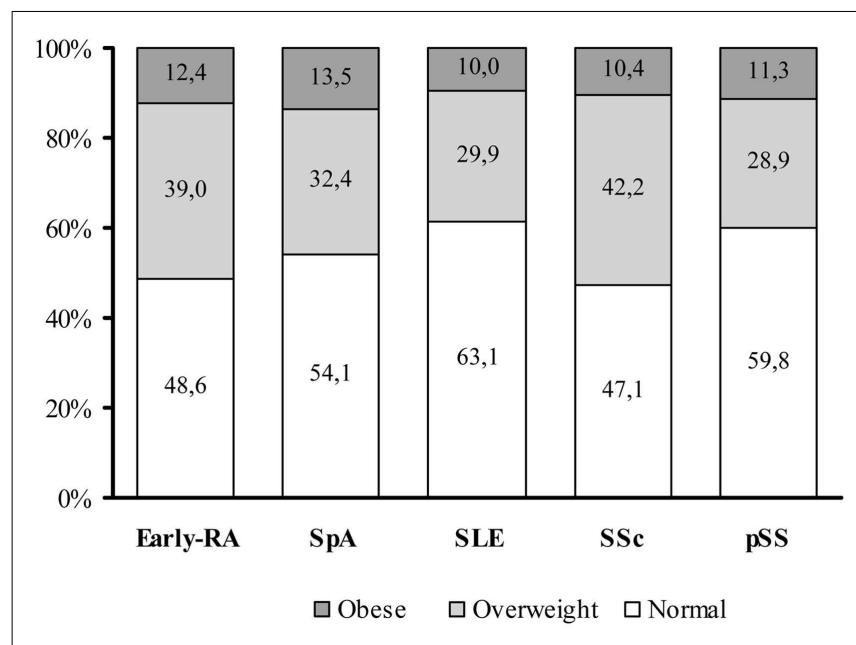

FIGURE 1 | Distribution of BMI categories among an Italian cohort of adult autoimmune disease patients. In our tertiary referral centre, the prevalence of overweight [defined according to the WHO International standards as a body mass index (BMI) of 25-29.9] or obesity (BMI $\geq 30$ ) is similar between the different autoimmune disease categories. The graph summarized data from an early-rheumatoid arthritis (early-RA) cohort of patients ( $N=401,76.3 \%$ female, mean age: $54.6 \pm 14.0$ years, mean $\mathrm{BMI}$ of $\left.25.3 \pm 4.4 \mathrm{Kg} / \mathrm{m}^{2}\right)$, a Spondyloarthritis (SpA) cohort $(N=220,30.6 \%$ female, mean age: $39.5 \pm 11.8$ years, mean BMI of $\left.25.1 \pm 4.4 \mathrm{Kg} / \mathrm{m}^{2}\right)$, a Systemic Lupus Erythematosus (SLE) cohort (506 patients, 90.3\% female, mean age: $44.1 \pm 14.8$ years, mean BMI of $24.0 \pm 4.6 \mathrm{Kg} / \mathrm{m}^{2}$ ), a Systemic Sclerosis (SSc) cohort (442 patients, $88.2 \%$ female, mean age: $58.5 \pm 14.2$ years, mean BMI of $24.4 \pm 4.8 \mathrm{Kg} / \mathrm{m}^{2}$ ), and a primary Sjogren Syndrome (pSS) cohort (204 patients, $96.1 \%$ female, mean age: $56.4 \pm 14.3$ years, mean $\mathrm{BMI}$ of $24.3 \pm 4.3 \mathrm{Kg} / \mathrm{m}^{2}$ ) (10). Data are reported as percentage (\%) of normal weight, overweight, and obesity in the different diseases.

rheumatic diseases in our tertiary referral center. In particular, the prevalence of obesity was $12.4 \%$ in patients with early Rheumatoid Arthritis (ERA), 13.5\% in seronegative spondyloarthritis (SpA), 10\% in Systemic Lupus Erythematosus (SLE), 10.4\% in Systemic Sclerosis (SSc), and $11.3 \%$ in primary Sjogren syndrome (pSS).

\section{OBESITY AND INFLAMMATION}

Adipose tissue in normal-weight subjects is composed mostly of adipocytes, i.e., the mature fat cells, and of the interadipocytes stromal vascular fraction including preadipocytes, i.e., the immature adipocyte precursors, fibroblasts, endothelial, and immune cells. Almost the full spectrum of immune cell types, and in particular macrophages, are represented among these AT-resident immune cells, and they play important housekeeping functions ranging from apoptotic cell clearance to extracellular matrix remodeling, tissue homeostasis maintenance, and angiogenesis (11).

The progressive and excessive fat accumulation that occurs in obesity leads to substantial changes in the amount and phenotype of the AT-resident immune cells, with an increasing in number and activity of some of them (most notably macrophages, mast cells, neutrophils, and $\mathrm{T}$ and $\mathrm{B}$ lymphocytes) while reducing others, including eosinophils and several subsets of $\mathrm{T}$ lymphocytes [T helper 2 (Th2), Treg, and iNKT cells] (12). This imbalance contributes to the development of obesity-related local and systemic inflammation and although most types of immune cells are already present in the AT, their number increases notably with the progression of obesity.

In particular, in obese status, macrophages are the most abundant cell type infiltrating fat tissue and they polarize from an antiinflammatory M2 macrophages pattern toward an inflammatory (M1) phenotype characterized by secretion of pro-inflammatory cytokines and expression of nitric oxide synthase sustaining the process of atherogenesis (13).

The link between metabolism and immunity was further corroborated at the intracellular level, with the main inflammatory signaling pathway comprising nuclear factor-kB (NF-kB) and inhibitor of $\mathrm{kB}$ kinase-b (IKKB) stimulated in obesity (14). Conversely, genetic deletion of IKKB or the inhibition of this pathway by salicylates was shown to attenuate insulin resistance in both mice and human beings (15). Furthermore, obesity-related inflammation tends to activate also other pro-inflammatory factors including the group of c-Jun $\mathrm{N}$-terminal protein kinases (JNK), while the ablation of JNK protects experimental animals from diet-induced obesity and inflammation (16).

Nowadays, there is a growing body of evidence that AT is a dynamic endocrine organ that releases several bioactive substances, secreted by adipocytes and adipose-resident macrophages, including some pro-inflammatory cytokines, in common with inflammatory diseases such as RA, like TNF- $\alpha$ and IL-6, and specific cytokines, termed "adipokines," most of which with proinflammatory properties accounting for a chronic low-grade systemic inflammation. Of note, these chronic inflammatory signals can have a profound impact on $\mathrm{CD}^{+}{ }^{+} \mathrm{T}$ cell populations, and it has been shown, in murine studies, that diet-induced obesity can impact specific fat-resident regulatory $\mathrm{T}$ cells (Treg) and particularly promote a Th17-biased immunity, partly dependent on IL-6.

The final picture appears to be characterized by an imbalance between Th1 and Th2 stimuli in fat, perhaps through the depletion of Th2 and AT Treg cells, the increase in $\mathrm{CD}^{+}$and Th1 cells or both. In addition, adipocytes were found to potently activate T-cells in an antigen- and contact-dependent manner that was enhanced in obesity, and MHCII-deficiency attenuated inflammatory and metabolic responses (17), and many studies have confirmed that the polarization state of an AT macrophages (ATM) correlates well with insulin resistance (18).

Of note, in a mouse model of collagen-induced arthritis with a diet-induced obesity, obese mice had an increased risk of developing arthritis and a more severe arthritis than lean mice. Although obesity does not display a pathogenic role in initiating arthritis, it could play an important role in amplifying the inflammation of arthritis through the Th1/Th17 response (19).

\section{ADIPOKINES AND INFLAMMATION}

Since the identification of leptin as the first bioactive molecule produced by AT, a growing body of data has accumulated about the plethora of adipokines produced by WAT (pre-adipocytes and mature adipocytes, as well as infiltrated macrophages), as the major contributors to the low-grade inflammatory state associated with obese condition.

The adipokine family has pleiotropic functions, mediating both endocrine and immune effects on multiple organs, most of which 
promoting metabolic dysfunctions and inflammatory responses. The association between obesity and chronic inflammation has introduced the idea that adipokines may contribute to the pathogenesis of several inflammatory conditions including rheumatic diseases, contributing to the complex network of inflammatory cascade $(20,21)$.

The role of adipokines in the mechanisms of rheumatic autoimmune diseases is supported by evidences that they exert potent modulatory actions on target tissues involved in rheumatic diseases including synovial, cartilage, bone, and immune cells. On the other hand, even if adipokines are produced predominantly by AT, they might also be expressed in the joints by chondrocytes, synoviocytes, and immune resident cells (22).

The characteristics and effects of more common adipokines are yet extensively described (23). Here, we briefly summarize the stronger evidences in understanding the role of the most relevant and most widely studied adipokines, i.e., adiponectin, leptin, resistin, visfatin, in the complex network of chronic inflammatory states and autoimmune rheumatic diseases.

\section{ADIPONECTIN}

Adiponectin is almost exclusively secreted by adipocytes and show anti-inflammatory, insulin-sensitizing, and anti-atherogenic properties (24). Obese people displayed low adiponectin plasma levels, suggesting that functional adipocytes in lean subjects produce high adiponectin levels, while in the dysfunctional adipocytes of obese individuals its expression is down-regulated.

On the side of inflammation, several "anti-inflammatory effects" of adiponectin have been reported. It modulates the activity of immune innate response by inducing the production of relevant anti-inflammatory factors such as IL-1 receptor antagonist and IL-10, suppresses TNF $\alpha$ production, promotes the antiinflammatory M2-phenotype macrophages polarization; also on adaptive immunity, adiponectin acts as a potent modulator of both $\mathrm{B}$ and T cells (25).

While in metabolic diseases, the role of adiponectin is clearly anti-inflammatory in rheumatic inflammatory diseases and its role is controversial. Unexpectedly, accumulating evidences on RA found that adiponectin was elevated in RA serum and synovial fluid, it is strongly expressed also at the sinovium level, directly correlate with disease activity and radiologic progression and it seems not affected by TNF blockade (26).

\section{LEPTIN}

The adipokine leptin, the product of the $o b$ gene, is mainly synthesized by WAT and is considered a major regulator of body weight by suppressing appetite, thus decreasing food intake, and stimulating energy expenditure. However, leptin plasma levels are directly correlated with the amount of body fat and obese people have high circulating leptin levels, indicating a resistance to its action in obese status (27).

Leptin is considered a pro-inflammatory cytokine, as its synthesis is enhanced during acute infection and inflammation, as well as under the action of inflammatory mediators such as TNF $\alpha$, IL-6, and IL-1 (28). Furthermore, leptin itself stimulates the production of pro-inflammatory cytokines from macrophages and increases the production of Th1 type cytokines, thus polarizing the Th1/Th2 balance toward a Th1 phenotype $(29,30)$.

Despite its pro-inflammatory profile, data on the role of leptin in RA remain controversial. In fact, there are studies with conflicting results regarding differences in circulating leptin levels between RA patients and controls and the association of leptin levels with disease activity (31), even if leptin seems to have a protective role against bone damage (32), as well as in animal models it is not clearly defined whether leptin has inducing or attenuating effects on arthritis development and severity (33).

\section{RESISTIN}

Resistin was initially thought related to insulin resistance studies in animal models; although evidence for this effect in human beings is less clear (34). Even if resistin production was originally described to be restricted only to WAT, subsequently it was observed that in human beings resistin mainly derives from circulating monocytes and macrophages (35), suggesting a major role in inflammatory processes in human beings.

In this regard, several studies demonstrated that resistin expression is up-regulated by pro-inflammatory cytokine, and in turn, resistin is able to stimulate the production of TNF $\alpha$, IL-6, IL12 TNF- $\alpha$, IL-1 $\beta$, and resistin itself (36). These evidences, together with the finding that the injection of resistin into mice joints triggers synovitis, highlight a potential role of resistin in the inflammatory cascade of inflammatory arthritis (36). In fact, in RA, serum, and synovial fluid resistin levels were higher than in osteoarthritis, as well as resistin expression in synovial lining layers. Moreover, resistin levels positively correlated with acute phase reactants and RA disease activity and seem modulated by anti-TNF therapy (37).

\section{VISFATIN}

Visfatin, initially named pre-B-cell colony-enhancing factor, is an adipokine with insulin-mimetic actions, preferentially produced by visceral AT (38). Circulating levels of visfatin correlates with the amount of visceral fat and are increased in patients with obesity and type- 2 diabetes and are reduced after weight loss (39).

Like resistin, visfatin is synthesized also in response to inflammatory stimuli and, on the other hand, it can enhances production of TNF- $\alpha$, IL- 6 , IL- $1 \beta$, as well as of IL-10 and IL-1Ra (40). Additionally, it promotes activation of $\mathrm{T}$ cells by enhancing the expression of co-stimulatory molecules, such as CD40, CD54, and CD80, on monocytes, acts as a chemotactic factor on monocytes and lymphocytes and it strongly affects the development of both T- and B-lymphocytes. As in other inflammatory conditions, in RA circulating levels of visfatin are increased, as well as its expression in synoviocytes at sites of attachment and invasion into cartilage or bone. In agreement with these findings, it is the association between radiographic damage and high visfatin serum concentrations. Visfatin serum and synovial fluid levels correlated with the degree of inflammation, with the severity of the disease, and with joint damage. Moreover, inhibition of visfatin in collagen-induced arthritis mice reduced arthritis severity with similar effect to that produced by TNF- $\alpha$ inhibitor (41). 


\section{PEDF AND CHEMERIN AS INFLAMMATORY ADIPOKINES IN OBESE PATIENTS WITH AUTOIMMUNE DISEASES}

The adipokine family is continuously growing and among the emerging adipokines, pigment epithelium-derived factor, and chemerin seem to be key players in linking obesity and inflammation in rheumatic diseases.

Pigment epithelium-derived factor (PEDF or SERPINF1) has been described as one of the new adipokines involved in the development of obesity-related disease. PEDF is a $50 \mathrm{kDa}$ secreted glycoprotein, member of the serpin (serine protease inhibitor) family lacking the serine-reactive loop and thus has no function on protease inhibition $(42,43)$. The PEDF protein was originally identified in retinal cell culture supernatants and characterized as a neurotropic factor (44), but recently, it has been associated with anti-tumor effects based on its anti-angiogenesis and proapoptosis activities (45). On the other hand, PEDF leads to insulin resistance and inflammatory signaling in several cell types (46-48).

The SERPINF1 gene is expressed in AT, liver, and bone marrow in human beings. Although the circulating levels of PEDF are thought to derive from the liver (49), to date it is well demonstrated that PEDF is up-regulated during adipogenesis and is mostly produced by mature adipocytes, suggesting that AT contributes to plasma PEDF levels $(50,51)$. This notion is consistent with studies indicating that PEDF is one of the most abundant protein secreted by human adipocytes or from human mesenchymal stem cells (48, 52). This direct association between serum PEDF levels and central obesity or the other components of the metabolic syndrome was well documented $(47,53-55)$.

Furthermore, in genetically and diet-induced obese mice, AT PEDF expression and plasma PEDF levels increased up to threefold whereas liver and skeletal muscle expressed only low amounts of PEDF, which did not increase upon obesity. In caloric restriction diet-induced obese mice, a reduction in AT PEDF expression was demonstrated (46).

In addition to its role in neurogenesis and angiogenesis, PEDF induces inflammatory signals in several cell lines and circulating PEDF levels correlate with the inflammatory burden and vascular dysfunction in individuals with type 1 diabetes $(45,52)$.

Consistent with this notion, the pathophysiology of obesity is characterized not only by the increased expression of inflammatory cytokines such as interleukin (IL)-6 and tumor necrosis factor (TNF)- $\alpha$ but also by the higher expression of PEDF and long-term obesity may inhibit regulatory responses resulting in a systemic pro-inflammatory state. Little is known about the regulation of PEDF expression and secretion but there is evidence of a possible involvement of hypoxia in human adipocytes (56).

Moreover, Chavas et al. demonstrated that PEDF directly activates inflammatory signaling proteins, p38 MAPK and ERK1/2, in macrophages, and activation of these inflammatory kinases was required for PEDF-mediated macrophage activation (57). In addition, PEDF mediates activation of pro-inflammatory signaling proteins, p38 MAPK and NF- $\kappa \mathrm{B}$, in muscle and fat cells in culture. Although PEDF has been considered as a major factor in the adipocyte culture contributing to macrophage activation, it is plausible that other factors, such as IL-1 or adipokines, may also lead to macrophage activation and synergistically enhance
TNF release (48). On the contrary, the protein deacetylase sirtuin1 (SirT1) plays a role in the repression of inflammation in AT, via suppression of JNK and NF-kB signaling disrupting adipocyte-macrophage communication $(58,59)$.

The inflammatory milieu of obesity is complex, featuring a panoply of elevated plasma and tissue specific cytokines that are increased in some rheumatic diseases and are able to increase the expression of inflammatory cytokines, such as TNF and IL6 , also in the early phases of the disease. Moreover, obesity is associated in some studies with an increased risk of rheumatic diseases $(60,61)$; and recent reports have showed a negative association between high BMI and response to anti-TNF agents in both RA and SpA (62-64), suggesting that fat mass may affect the response to biologic agents. Pathophysiological mechanisms by which BMI influences anti-TNF biological drugs response remain still unclear.

To support the possible role of PEDF as a player in inflammatory burden of RA, we observed that the circulating PEDF levels, evaluated in a cohort of patients with early RA at the time of RA diagnosis, are higher in obese and overweight than in normalweight subjects and correlated with systemic inflammation (ESR and CRP) (65).

In recent years, another adipokine, named chemerin, has emerged has a key adipokine involved in inflammation and immune responses in RA. Chemerin is involved in adipogenesis, chemotaxis, and activation of dendritic cells and macrophages. In healthy conditions, the overweight and obese subjects have higher levels of circulating chemerin compared to normal-weight subjects, which decrease after reduction of fat mass as a result of a dietary route $(66,67)$.

Chemerin is found in inflamed tissues and biological fluids of different inflammatory diseases, such as RA. Recent studies have shown that synovial fibroblasts (FLSs) of RA patients express chemerin and its receptor (ChemR23) and that circulating levels of this molecule directly correlate with disease activity $(68,69)$. The expression of ChemR23 on RA fibroblasts and chemerin itself activate FLSs to enhance the production of IL-6 and CCL2 (7072). Therefore, these observations indicate that chemerin may be involved in the enhancement of local pro-inflammatory cytokine and chemokine production by RA FLSs, leading to persistent amplification of inflammation in the RA synovium, possibly in an autocrine or paracrine manner. Recently, $\mathrm{Ha}$ et al. found that chemerin levels directly correlate with disease activity in RA (73). However, it is not yet completely clear whether the circulating levels of chemerin in patients with RA are more associated with systemic inflammation or AT itself, but it is confirmed its role as a biomarker of disease activity.

In this regard, adipokines, i.e., PEDF and chemerin, may provide a metabolic link between obesity and RA or other autoimmune diseases, and as such they could be possible biomarkers of the effect of weight loss and of the decreased fat tissue in chronic inflammatory diseases. In fact, new evidences has emerged to suggest that weight loss may lead to an improvement of quality of life and a reduction of inflammation and of systemic inflammatory mediators in patients with obesity and RA after weight loss and metabolic control with a dietary intervention. 


\section{IMPACT OF OBESITY ON AUTOIMMUNE CHRONIC INFLAMMATORY DISEASES \\ RA AND OBESITY}

Obesity in RA was found prevalent in $18-31 \%$ of patients, overall slightly higher than in the general population. An overweight condition has been noted in more than $60 \%$ of RA patients $(74,75)$.

\section{RA incidence}

In the past years, several studies evaluated the impact of obesity on RA incidence, but with inconclusive results, probably due to small size number of patients included and to the low prevalence of obesity $(61,76-78)$. More recently, a large retrospective case-control study showed that obesity is associated with a modest risk of developing RA (OR:1.24; 95\% CI: 1.01, 1.53 adjusted for smoking status), but about $50 \%$ of the increasing incidence of RA among this population from Minnesota could be attributed to the obesity and this effect is more pronounced in woman (79).

Moreover, data from three different cohorts of patients seem to indicate that obesity is associated with a likelihood of developing a seronegative RA, with an OR between 1.6 and $3.45(78,80$, 81). In particular, in a large Swedish case-control study, dividing patients according to the ACPA (anti-citrullinated protein antibody) positivity, the RA risk linked to obesity appears different between genders; in fact, only the female gender was associated with the occurrence of ACPA-negative RA and there was no association between obesity and ACPA-positive RA among women, while an inverse association between BMI and ACPA-positive RA was seen in men (80).

In a recent study involving two large prospective cohorts of women (Nurses' Health Study-NHS 109,896 woman and Nurses' Health Study II-NHSII, 108,727 woman, with 1,181 incident cases of RA), Lu et al. observed a significant association between being overweight and obese and developing RA, both in seropositive and seronegative subset. This association was even stronger among women diagnosed at younger ages, i.e., $\leq 55$ years, with a $35 \%$ increased risk of developing RA, and an almost $50 \%$ increased risk of developing seropositive RA in adulthood. Interestingly, also the "exposure time" to obesity seems to influence the RA risk in woman aged 55 or younger with a $37 \%$ increased risk of RA with a history of 10 years of being obese (82).

\section{RA activity and severity}

Considering the effects of obesity on RA activity and severity, published data suggest a negative influence of a high BMI on disease activity. In a large cohort of early RA followed-up for an average of 9.5 years, at the study inclusion obese subjects had slightly higher HAQ, VAS pain and global health scores than patients with a BMI $<30$, with similar DAS28 and systemic inflammatory indexes (ESR, CRP). In the same cohort, at the last follow-up, obese people had a more active and severe disease, with a decreased probability of being in disease remission and of reaching sustained remission, despite similar use of DMARDs, steroids, and biologic drugs in different BMI groups (83). The association between worst disease activity and disability was confirmed also in other cohorts of patients with established RA $(84,85)$.
In a sub-analysis of the BeST study evaluating the effects of a BMI $>25$ on response to therapy in patients with early RA (disease duration $<3$ years) naïve to DMARDs, subjects with a BMI under or over 25 had no differences in baseline DAS, inflammatory parameters, HAQ, pain, and global health assessment (86). In our cohort of 346 early RA with symptoms duration $<12$ months, we observed that disease activity indexes (DAS and DAS28) were higher in obese and overweight patients compared to normal-weight patients (87).

Regarding disability, like in the general population, worsening functional capacity and quality of life has been linked to increased fat mass and, both in the general population and in patients with RA, pain prevalence, and severity have been linked to obesity; pain in RA has a large impact on self-reported health, physical function, and disease activity index $(88,89)$.

Moreover, it can be hypothesized that adiposity may influence also the evaluation of swollen joint, but Caplan et al. showed that the swollen joint count performs in obese subjects at least as well as in subjects with lower BMI (90). Moreover, as previously discussed, the worst disease activity and severity in obese RA patients can be derived from the close association of obesity with activation of pro-inflammatory pathways.

Despite the evidences of a more severe disease, data on radiographic progression suggest that obesity may be protective against joint damage (91-94). Studies in patients with early RA, of up to 3-year duration, suggest that the protective effect of high BMI seems to be present before the diagnosis of RA, with overweight and obese RA patients exhibiting less joint damage than their normal-weight counterparts at the time of diagnosis; this effect appears to continue during the first years of RA, with joint damage progressing less rapidly in obese than in normal-weight RA patients (94). The possible reasons for this finding may include an increase mechanical load stimulating bone synthesis, as suggested for the protective effect of obesity from osteoporosis development in the general population, a lower joint destruction in seronegative RA, the RA subset more associated with obesity, higher levels of estrogens found in obese subjects, having a bone protective effects, and role of adipokines, in particular adiponectin. As previously discussed, adiponectin might induce disease activity in the joint, resulting in more active disease in lean having higher adiponectin levels and less active in obese patients that displayed lower adiponectin levels (95). However, this finding has to be further clarified.

\section{Obesity and $R A$ response to therapy}

Regarding the impact of high BMI on response to RA treatments, all the published studies showed that obesity represents an additional risk of poor response to therapy and of not reaching remission. In first studies conducted on long standing RA, obese patients were $50 \%$ less likely to obtain disease remission after 12 months of a first-line anti-TNF treatment than normalweight subjects, and the worst outcome was observed with the weight-dosed drug, i.e., infliximab $(62,63,96)$.

Similar results were confirmed by observational studies including early-RA patients, in whom both obesity and overweight confer a lower chance to obtain remission or low disease activity, irrespective of treatment with DMARDs or anti-TNF therapy $(86,97,98)$. 
Moreover, more than twice overweight and obese subjects with Early-RA needed anti-TNF therapy after 12 months from diagnosis, compared to normal-weight patients (87).

The reason why obesity affects the RA outcomes, in particular in patients treated with infliximab needs to be clarified. Mechanisms that can be postulated are a direct influence of obesity on drug pharmacokinetics and an inflammatory and therapyresistant state induced by AT by the release of specific adipocytokines that are increased in RA patients and are able to increase the expression of inflammatory cytokines, such as TNF and IL-6. In this regard, however, studies testing the effect of TNF blockade on adipokine plasma levels in patients with RA are not conclusive, and the majority of the studies show that anti-TNF drugs have no influence on the levels of adipocytokines (99). However, the AT may be associated with an induction of resistance to all of the anti-TNF drugs, and understanding its role requires further research. Regarding infliximab, it has recently been shown that Fc receptors modulate the efficacy of infliximab both in vitro and ex vivo, whereas the presence of this receptor has no impact on the inhibitory activity of certolizumab-pegol, which lacks the Fc fragment (100). These data could be helpful in the light of the fact that omental adipocytes show high expression of Fc receptors (101).

\section{SPA AND PsA AND OBESITY}

Seronegative SpA are a heterogeneous group of inflammatory diseases including ankylosing spondylitis (AS), PsA, inflammatory bowel disease associated SpA (EnteroSpA), and undifferentiated SpA (USpA), sharing some clinical characteristics, in particular the involvement of axial spine. At present, only a very few studies has evaluated the impact of body weight on SpA, focusing on axial involvement. In a cohort of 155 patients affected by AS starting treatment with Infliximab at the dosage of $5 \mathrm{mg} / \mathrm{Kg}$, Ottaviani et al. reported that the response to therapy (BASDAI50) at 6 months was significantly lower in obese $(26.5 \%)$ than in normalweight (77.6\%) individuals (64). In another study involving 170 patients affected by a form of SpA with axial involvement treated with a first-line anti-TNF therapy, the proportion of axial SpA patients reaching the BASDAI50 after 12 months fell from $72.8 \%$ in normal weight to $54.5 \%$ in overweight and $30.4 \%$ in obese subjects (102); the lower response rate according to BMI was obtained under Infliximab treatment.

Psoriatic arthritis, although part of the SpA group, deserves a separate discussion. More extensive studies are available on PsA and psoriasis, conditions associated with a high prevalence of metabolic syndrome and other metabolic disorders. Both PsA and psoriasis has been associated with an enhanced prevalence of obesity and overweight. A recent meta-analysis including 201,831 psoriatic patients on a total of 2.1 million subjects conclude that psoriatic patients are at significantly higher risk of obesity compared with the general population, with an OR from 1.46 for patients with mild psoriasis to 2.23 for severe-psoriasis (103).

Bhole et al. evaluating patients with PsA, psoriasis, and RA, found that in all these conditions mean BMI and prevalence of obesity were higher compared to the general population, in which BMI was 26.1 and obese people 18\%. Interestingly, BMI values were similar between RA and psoriasis patients, while PsA patients have higher BMI values than those with psoriasis or RA $(29.6,27.9$, and $27.3 \mathrm{Kg} / \mathrm{m}^{2}$, respectively) and the prevalence of obesity was $37 \%$ in PsA, 29\% in psoriasis, and 27\% in RA (104).

The effects of these two metabolic and autoimmune disorders are probably bidirectional, as there are evidences supporting that obesity may be a risk factor predisposing to the development of psoriasis and PsA, while others suggesting that overweight could be a consequence of these conditions rather than a predisposing factor. However, obesity is a well recognized risk factor for the development of psoriasis and PsA. In a large population of 75,395 individuals with psoriasis, obesity has been associated with a high risk of incident PsA (105).

Only few studies assessed the relationship between obesity and the severity of arthritis in patients with PsA. Di Minno et al. reported that increased BMI predicted less favorable response to $\mathrm{TNF} \alpha$ blockers in patients with PsA who were followed for 24 months (106); and Eder et al. found that overweight and obesity are associated with a lower probability of achieving MDA among patients with PsA, independently of the use of biological and non-biological DMARDs (107).

Of particular interest and of crucial clinical relevance is the effect of weight loss on inflammation and disease outcome. The few studies evaluating interventions aiming at lowering the body weight showed significant improvement of psoriasis or PsA severity, as well as the cardiovascular risk profile in both diseases. Weight reduction was also associated with improved response to treatment with TNF $\alpha$ blockers (108-110).

\section{CONNECTIVE SYSTEMIC TISSUE DISEASES: SLE, SSc AND pSS AND OBESITY}

The prevalence of obesity in SLE is between 28 and 50\% $(111,112)$. Some studies investigated the impact of BMI on SLE, evidencing conflicting results about a relationship between BMI and the disease manifestations (113-115). Data from the different cohorts showed that about two-thirds of patients with SLE were either overweight or obese but contrasting data have been reported about an association between overweight and obesity and disease activity in SLE patients (116). On the other hand, an increased BMI has shown to be associated with older age, less social support, depression, poorer self-reported QoL, and fatigue in patients with SLE (117).

It has been well established that SLE is associated with an increased risk of cardiovascular disease as compared with general population and the Framingham cardiovascular risk score was significantly higher in SLE women classified as obese compared to normal-weight patients. Increased waist circumference increases the risk of atherosclerosis and the incidence of arterial and venous thromboembolism in patients with $\operatorname{SLE}(118,119)$.

Finally, there was a statistically significant association between BMI in the SLE patients and the presence of lupus nephritis and hypertension (120). This is important because hypertension is a strong risk factor for cardiovascular disease, which is one of the major causes of death in $\operatorname{SLE}(121,122)$.

The prevalence of obesity in SSc is between 9 and $18 \%$. This lower percentage of obesity in SSc than in normal population was observed mainly in women with diffuse SSc, but not in those with limited SSc (123). In SSc patients, visceral abdominal fat has been correlated with cardiovascular risk factors and lung functionality, 
as already found in a large population of elderly men and women (124-126).

Considering that SSc is a form of micro- and macro-vascular angiopathy the presence of obesity should be regarded as an additive factor in terms of cardiovascular risk. On the contrary, a low BMI, together with age $\geq 65$ years, low forced vital capacity ( $<50 \%$ of the predicted value), clinically significant arrhythmia on electrocardiogram, absence of anticentromere antibodies, hypertension, chest radiograph suggestive of pulmonary fibrosis, has been demonstrated to be a predictor of mortality in early SSc (127).

To date, no data are reported about the involvement of obesity in pSS and its effects. A recent study on a multicentre cohort of UK pSS patients demonstrated that pain and depression were the most important predictors of the health-related quality of life in patients with pSS, accounting for $48 \%$ of the variability. Moreover, BMI, fatigue, and anxiety had been identified as significant predictors, but accounting for $<5$ of the variability in terms of EuroQoL-5 dimension utility values (128).

\section{CONCLUSIVE REMARISS}

Obesity is a risk factor for many inflammatory and autoimmune diseases, in terms of incidence, disease severity, and outcomes, as well as for the overall cardiovascular risk.

Research in the field of obesity and its related effects is continuously growing and the knowledge of these issues has increased significantly in recent years. Understanding even more deeply the pathophysiologic mechanisms underlying the interaction between obesity, inflammation, and disease pathways appears to be of upmost importance to improve the outcomes in patients with rheumatic diseases.

This overview provides a rationale for further studies on the role of AT in RA and the mechanisms behind weight changes during the course of RA disease, as well as the potential effect of weight control on the efficacy of medication disease severity, and complications.

Evaluating the effects of weight loss on the inflammatory/autoimmune disease course appears to be crucial in terms of potential clinical and also pharmacoeconomics perspectives.

\section{REFERENCES}

1. Swinburn BA, Sacks G, Hall KD, McPherson K, Finegood DT, Moodie ML, et al. The global obesity pandemic: shaped by global drivers and local environments. Lancet (2011) 378:804-14. doi:10.1016/S0140-6736(11)60813-1

2. Hauner H. Secretory factors from human adipose tissue and their functional role. Proc Nutr Soc (2005) 64:163-9. doi:10.1079/PNS2005428

3. van der Meer JW, Netea MG. A salty taste to autoimmunity. $N$ Engl J Med (2013) 368:2520-1. doi:10.1056/NEJMcibr1303292

4. World Health Organization. Health Topics: Obesity. Geneva: World Health Organization (2011). Available from: http://www.who.int/topics/obesity/en/

5. National Institutes of Health (NIH), National Heart, Lung, and Blood Institute (NHLBI). Clinical guidelines on the identification, evaluation and treatment of overweight and obesity in adults: the evidence report. Obes Res (1998) 6:51S-209S.

6. Grundy SM, Brewer HB Jr, Cleeman JI, Smith SC Jr, Lenfant C; American Heart Association, et al. Definition of metabolic syndrome: report of the National Heart, Lung, and Blood Institute/American Heart Association conference on scientific issues related to definition. Circulation (2004) 109:433-8. doi:10.1161/01.CIR.0000111245.75752.C6

7. Stavropoulos-Kalinoglou A, Metsios GS, Koutedakis Y, Nevill AM, Douglas $\mathrm{KM}$, Jamurtas A, et al. Redefining overweight and obesity in rheumatoid arthritis patients. Ann Rheum Dis (2007) 66:1316-21. doi:10.1136/ard.2006. 060319

8. Katz PP, Yazdany J, Trupin L, Schmajuk G, Margaretten M, Barton J, et al. Sex differences in assessment of obesity in rheumatoid arthritis. Arthritis Care Res (2013) 65:62-70. doi:10.1002/acr.21810

9. Keys A, Fidanza F, Karvonen MJ, Kimura N, Taylor HL. Indices of relative weight and obesity. Int J Epidemiol (2014) 43:655-65. doi:10.1093/ije/ dyu058

10. De Luca G, Gremese E, Messuti L, Bosello SL, Fedele AL, Gigante MR, et al. Distribution of body mass index and metabolic syndrome in patients with inflammatory autoimmune diseases from a single Italian centre. Ann Rheum Dis (2013) 72:744. doi:10.1136/annrheumdis-2013-eular.1060

11. Schipper HS, Prakken B, Kalkhoven E, Boes M. Adipose tissue-resident immune cells: key players in immunometabolism. Trends Endocrinol Metab (2012) 23:407-15. doi:10.1016/j.tem.2012.05.011

12. Cildir G, Akıncilar SC, Tergaonkar V. Chronic adipose tissue inflammation: all immune cells on the stage. Trends Mol Med (2013) 19:487-500. doi:10.1016/j.molmed.2013.05.001

13. Lumeng CN, DelProposto JB, Westcott DJ, Saltiel AR. Phenotypic switching of adipose tissue macrophages with obesity is generated by spatiotemporal differences in macrophage subtypes. Diabetes (2008) 57:3239-46. doi:10.2337/ db08-0872

14. Shoelson SE, Lee J, Yuan M. Inflammation and the IKK beta/I kappa B/NFkappa B axis in obesity- and diet-induced insulin resistance. Int J Obes Relat Metab Disord (2003) 27(Suppl 3):S49-52. doi:10.1038/sj.ijo.0802501

15. Yuan M, Konstantopoulos N, Lee J, Hansen L, Li ZW, Karin M, et al. Reversal of obesity- and diet-induced insulin resistance with salicylates or targeted disruption of Ikkbeta. Science (2001) 293:1673-7. doi:10.1126/science. 1061620

16. Solinas G, Vilcu C, Neels JG, Bandyopadhyay GK, Luo JL, Naugler W, et al. JNK1 in hematopoietically derived cells contributes to diet-induced inflammation and insulin resistance without affecting obesity. Cell Metab (2007) 6:386-97. doi:10.1016/j.cmet.2007.09.011

17. Deng T, Lyon CJ, Minze LJ, Lin J, Zou J, Liu JZ, et al. Class II major histocompatibility complex plays an essential role in obesity-induced adipose inflammation. Cell Metab (2013) 17:411-22. doi:10.1016/j.cmet.2013.02.009

18. Osborn O, Olefsky JM. The cellular and signaling networks linking the immune system and metabolism in disease. Nat Med (2012) 18:363-74. doi: $10.1038 / \mathrm{nm} .2627$

19. Jhun JY, Yoon BY, Park MK, Oh HJ, Byun JK, Lee SY, et al. Obesity aggravates the joint inflammation in a collagen-induced arthritis model through deviation to Th17 differentiation. Exp Mol Med (2012) 44:424-31. doi:10.3858/emm.2012. 44.7.047

20. Muller-Ladner U, Neumann E. Rheumatoid arthritis: the multifaceted role of adiponectin in inflammatory joint disease. Nat Rev Rheumatol (2009) 5:659-60. doi:10.1038/nrrheum.2009.232

21. Stavropoulos-Kalinoglou A, Metsios GS, Koutedakis Y, Kitas GD. Obesity in rheumatoid arthritis. Rheumatology (2011) 50:450-62. doi:10.1093/ rheumatology/keq266

22. Gómez R, Conde J, Scotece M, Gómez-Reino JJ, Lago F, Gualillo O. What's new in our understanding of the role of adipokines in rheumatic diseases? Nat Rev Rheumatol (2011) 7:528-36. doi:10.1038/nrrheum.2011.107

23. Abella V, Scotece M, Conde J, López V, Lazzaro V, Pino J, et al. Adipokines, metabolic syndrome and rheumatic diseases. J Immunol Res (2014) 2014:343746. doi:10.1155/2014/343746

24. Stofkova A. Leptin and adiponectin: from energy and metabolic dysbalance to inflammation and autoimmunity. Endocr Regul (2009) 43:157-68.

25. Kadowaki T, Yamauchi T. Adiponectin and adiponectin receptors. Endocr Rev (2005) 26:439-51. doi:10.1210/er.2005-0005

26. Frommer KW, Zimmermann B, Meier FM, Schröder D, Heil M, Schäffler A, et al. Adiponectin-mediated changes in effector cells involved in the pathophysiology of rheumatoid arthritis. Arthritis Rheum (2010) 62:2886-99. doi:10.1002/art.27616

27. Jéquier E. Leptin signaling, adiposity, and energy balance. Ann N Y Acad Sci (2002) 967:379-88. doi:10.1111/j.1749-6632.2002.tb04293.x

28. Otero M, Lago R, Lago F, Casanueva FF, Dieguez C, Gómez-Reino JJ, et al. Leptin, from fat to inflammation: old questions and new insights. FEBS Lett (2005) 579:295-301. doi:10.1016/j.febslet.2004.11.024 
29. Otero M, Lago R, Gomez R, Dieguez C, Lago F, Gómez-Reino J, et al. Towards a proinflammatory and immunomodulatory emerging role of leptin. Rheumatology (2006) 45:944-50. doi:10.1093/rheumatology/kel157

30. Lord GM, Matarese G, Howard JK, Baker RJ, Bloom SR, Lechler RI. Leptin modulates the T-cell immune response and reverses starvation-induced immunosuppression. Nature (1998) 394:897-901. doi:10.1038/29795

31. Del Prete A, Salvi V, Sozzani S. Adipokines as potential biomarkers in rheumatoid arthritis. Mediators Inflamm (2014) 2014:425068. doi:10.1155/ 2014/425068

32. Rho YH, Solus J, Sokka T, Oeser A, Chung CP, Gebretsadik T, et al. Adipocytokines are associated with radiographic joint damage in rheumatoid arthritis. Arthritis Rheum (2009) 60:1906-14. doi:10.1002/art.24626

33. Otvos L Jr, Shao WH, Vanniasinghe AS, Amon MA, Holub MC, Kovalszky I, et al. Toward understanding the role of leptin and leptin receptor antagonism in preclinical models of rheumatoid arthritis. Peptides (2011) 32:1567-74. doi:10.1016/j.peptides.2011.06.015

34. Heilbronn LK, Rood J, Janderova L, Albu JB, Kelley DE, Ravussin E, et al. Relationship between serum resistin concentrations and insulin resistance in nonobese, obese, and obese diabetic subjects. J Clin Endocrinol Metab (2004) 89:1844-8. doi:10.1210/jc.2003-031410

35. Savage DB, Sewter CP, Klenk ES, Segal DG, Vidal-Puig A, Considine RV, et al. Resistin/Fizz3 expression in relation to obesity and peroxisome proliferatoractivated receptor-gamma action in humans. Diabetes (2001) 50:2199-202. doi:10.2337/diabetes.50.10.2199

36. Bokarewa M, Nagaev I, Dahlberg L, Smith U, Tarkowski A. Resistin, an adipokine with potent proinflammatory properties. J Immunol (2005) 174:5789-95. doi:10.4049/jimmunol.174.9.5789

37. Senolt L, Housa D, Vernerová Z, Jirásek T, Svobodová R, Veigl D, et al. Resistin in rheumatoid arthritis synovial tissue, synovial fluid and serum. Ann Rheum Dis (2007) 66:458-63. doi:10.1136/ard.2006.054734

38. Sethi JK, Vidal-Puig A. Visfatin: the missing linkbetween intra-abdominal obesity and diabetes? Trends Mol Med (2005) 11:344-7. doi:10.1016/j.molmed. 2005.06.010

39. Haider DG, Schindler K, Schaller G, Prager G, Wolzt M, Ludvik B. Increased plasma visfatin concentrations in morbidly obese subjects are reduced after gastric banding. J Clin Endocrinol Metab (2006) 91:1578-81. doi:10.1210/jc. 2005-2248

40. Moschen AR, Kaser A, Enrich B, Mosheimer B, Theurl M, Niederegger H, et al. Visfatin, an adipocytokine with proinflammatory and immunomodulating properties. J Immunol (2007) 178:1748-58. doi:10.4049/jimmunol.178.3.1748

41. Evans L, Williams AS, Hayes AJ, Jones SA, Nowell M. Suppression of leukocyte infiltration and cartilage degradation by selective inhibition of preB cell colony-enhancing factor/visfatin/nicotinamide phosphoribosyltransferase: Apo866-mediated therapy in human fibroblasts and murine collageninduced arthritis. Arthritis Rheum (2011) 63:1866-77. doi:10.1002/art.30338

42. Steele FR, Chader GJ, Johnson LV, Tombran-Tink J. Pigment epitheliumderived factor: neurotrophic activity and identification as a member of the serine protease inhibitor gene family. Proc Natl Acad Sci U S A (1993) 90:1526-30. doi:10.1073/pnas.90.4.1526

43. Becerra SP, Sagasti A, Spinella P, Notario V. Pigment epithelium-derived factor behaves like a noninhibitory serpin. Neurotrophic activity does not require the serpin reactive loop. J Biol Chem (1995) 270:25992-9. doi:10.1074/jbc.270.43. 25992

44. Tombran-Tink J, Chader GG, Johnson LV. PEDF: a pigment epitheliumderived factor with potent neuronal differentiative activity. Exp Eye Res (1991) 53:411-4. doi:10.1016/0014-4835(91)90248-D

45. Fernandez-Garcia NI, Volpert OV, Jimenez B. Pigment epithelium-derived factor as a multifunctional antitumor factor. J Mol Med (2007) 85:15-22. doi:10.1007/s00109-006-0111-z

46. Crowe S, Wu LE, Economou C, Turpin SM, Matzaris M, Hoehn KL, et al. Pigment epithelium-derived factor contributes to insulin resistance in obesity. Cell Metab (2009) 10:40-7. doi:10.1016/j.cmet.2009.06.001

47. Filleur S, Nelius T, de Riese W, Kennedy RC. Characterization of PEDF: a multi-functional serpin family protein. J Cell Biochem (2009) 106:769-75. doi:10.1002/jcb.22072

48. Famulla S, Lamers D, Hartwig S, Passlack W, Horrighs A, Cramer A, et al. Pigment epithelium-derived factor (PEDF) is one of the most abundant proteins secreted by human adipocytes and induces insulin resistance and inflammatory signaling in muscle and fat cells. Int J Obes (2011) 35:762-72. doi:10.1038/ijo.2010.212

49. Matsumoto K, Ishikawa H, Nishimura D, Hamasaki K, Nakao K, Eguchi K. Antiangiogenic property of pigment epithelium-derived factor in hepatocellular carcinoma. Hepatology (2004) 40:252-9. doi:10.1002/hep.20259

50. Zvonic S, Lefevre M, Kilroy G, Floyd ZE, DeLany JP, Kheterpal I, et al. Secretome of primary cultures of human adipose-derived stem cells: modulation of serpins by adipogenesis. Mol Cell Proteomics (2007) 6:18-28. doi:10.1074/mcp.M600217-MCP200

51. Sabater M, Moreno-Navarrete JM, Ortega FJ, Pardo G, Salvador J, Ricart W, et al. Circulating pigment epithelium-derived factor levels are associated with insulin resistance and decrease after weight loss. Clin Endocrinol Metab (2010) 95:4720-8. doi:10.1210/jc.2010-0630

52. Chiellini C, Cochet O, Negroni L, Samson M, Poggi M, Ailhaud G, et al. Characterization of human mesenchymal stem cell secretome at early steps of adipocyte and osteoblast differentiation. BMC Mol Biol (2008) 9:26. doi:10.1186/1471-2199-9-26

53. Yamagishi S, Adachi H, Abe A, Yashiro T, Enomoto M, Furuki K, et al. Elevated serum levels of pigment epithelium-derived factor in the metabolic syndrome. J Clin Endocrinol Metab (2006) 91:2447-50. doi:10.1210/jc.20052654

54. Wang P, Smit E, Brouwers MC, Goossens GH, van der Kallen CJ, van Greevenbroek MM, et al. Plasma pigment epithelium-derived factor is positively associated with obesity in Caucasian subjects, in particular with the visceral fat depot. Eur J Endocrinol (2008) 159:713-8. doi:10.1530/EJE-08-0521

55. Jenkins A, Zhang SX, Gosmanova A, Aston C, Dashti A, Baker MZ, et al. Increased serum pigment epithelium derived factor levels in type 2 diabetes patients. Diabetes Res Clin Pract (2008) 82:e5-7. doi:10.1016/j.diabres.2008. 06.019

56. Lange J, Yafai Y, Reichenbech A, Wiedemann P, Eichler W. Regulation of epithelium-derived factor production and release by retinal glial (Muller) cells under hypoxia. Invest Ophthalmol Vis Sci (2008) 49:5161-7. doi:10.1167/iovs. 08-2201

57. Chavan SS, Hudson LK, Li JH, Ochani M, Harris Y, Patel NB, et al. Identification of pigment epithelium-derived factor as an adipocyte-derived inflammatory factor. Mol Med (2012) 18:1161-8. doi:10.2119/molmed.2012.00156

58. Yoshizaki T, Schenk S, Imamura T, Babendure JL, Sonoda N, Bae EJ, et al. SIRT1 inhibits inflammatory pathways in macrophages and modulates insulin sensitivity. Am J Physiol Endocrinol Metab (2010) 298:E419-28. doi:10.1152/ ajpendo.00417.2009

59. Gillum MP, Kotas ME, Erion DM, Kursawe R, Chatterjee P, Nead KT, et al. SirT1 regulates adipose tissue inflammation. Diabetes (2011) 60:3235-45. doi:10.2337/db11-0616

60. Voigt LF, Koepsell TD, Nelson JL, Dugowson CE, Daling JR. Smoking, obesity, alcohol consumption, and the risk of rheumatoid arthritis. Epidemiology (1994) 5:525-32.

61. Symmons DP, Bankhead CR, Harrison BJ, Brennan P, Barrett EM, Scott DG, et al. Blood transfusion, smoking, and obesity as risk factors for the development of rheumatoid arthritis: results from a primary care-based incident case-control study in Norfolk, England. Arthritis Rheum (1997) 40:1955-61. doi:10.1002/art.1780401106

62. Klaasen R, Wijbrandts CA, Gerlag DM, Tak PP. Body mass index and clinical response to infliximab in rheumatoid arthritis. Arthritis Rheum (2011) 63:359-64. doi:10.1002/art.30136

63. Gremese E, Carletto A, Padovan M, Atzeni F, Raffeiner B, Giardina AR, et al. Obesity and reduction of the response rate to anti-tumor necrosis factor alpha in rheumatoid arthritis: an approach to personalized medicine. Arthritis Care Res (2013) 65:94-100. doi:10.1002/acr.21768

64. Ottaviani S, Allanore Y, Tubach F, Forien M, Gardette A, Pasquet B, et al. Body mass index influences the response to infliximab in ankylosing spondylitis. Arthritis Res Ther (2012) 14:R115. doi:10.1186/ar3841

65. Gremese E, Tolusso B, Fedele AL, Gigante MR, Carbonella A, Canestri S, et al. Metaflammation, PEDF and chemerin: potential systemic factors which link obesity to response to therapy in early rheumatoid arthritis. Ann Rheum Dis (2014) 73(Suppl 2). doi:10.1136/annrheumdis-2014-eular.4936

66. Bozaoglu K, Bolton K, McMillan J, Zimmet P, Jowett J, Collier G, et al. Chemerin is a novel adipokine associated with obesity and metabolic syndrome. Endocrinology (2007) 148:4687-94. doi:10.1210/en.2007-0175 
67. Sell H, Divoux A, Poitou C, Basdevant A, Bouillot JL, Bedossa P, et al. Chemerin correlates with markers for fatty liver in morbidly obese patients and strongly decreases after weight loss induced by bariatric surgery. J Clin Endocrinol Metab (2010) 95:2892-6. doi:10.1210/jc.2009-2374

68. Eisinger K, Bauer S, Schäffler A, Walter R, Neumann E, Buechler C, et al. Chemerin induces CCL2 and TLR4 in synovial fibroblasts of patients with rheumatoid arthritis and osteoarthritis. Exp Mol Pathol (2012) 92:90-6. doi:10.1016/j.yexmp.2011.10.006

69. Kaneko K, Miyabe Y, Takayasu A, Fukuda S, Miyabe C, Ebisawa M, et al. Chemerin activates fibroblast-like synoviocytes in patients with rheumatoid arthritis. Arthritis Res Ther (2011) 13:R158. doi:10.1186/ar3475

70. Brennan FM, McInnes IB. Evidence that cytokines play a role in rheumatoid arthritis. J Clin Invest (2008) 118:3537-45. doi:10.1172/JCI36389

71. Kishimoto T. Interleukin-6: from basic science to medicine: 40 years in immunology. Annu Rev Immunol (2005) 23:1-21. doi:10.1146/annurev. immunol.23.021704.115806

72. Iwamoto T, Okamoto H, Toyama Y, Momohara S. Molecular aspects of rheumatoid arthritis: chemokines in the joints of patients. FEBS J (2008) 275:4448-55. doi:10.1111/j.1742-4658.2008.06580.x

73. Ha YJ, Kang EJ, Song JS, Park YB, Lee SK, Choi ST. Plasma chemerin levels in rheumatoid arthritis are correlated with disease activity rather than obesity. Joint Bone Spine (2014) 81:189-90. doi:10.1016/j.jbspin.2013.07.013

74. Naranjo A, Sokka T, Descalzo MA, Calvo-Alén J, Hørslev-Petersen K, Luukkainen RK, et al. Cardiovascular disease in patients with rheumatoid arthritis: results from the QUEST-RA study. Arthritis Res Ther (2008) 10:R30. doi:10.1186/ar2383

75. Armstrong DJ, McCausland EM, Quinn AD, Wright GD. Obesity and cardiovascular risk factors in rheumatoid arthritis. Rheumatology (2006) 45:782. doi:10.1093/rheumatology/kel124

76. Hernandez Avila M, Liang MH, Willett WC, Stampfer MJ, Colditz GA, Rosner $\mathrm{B}$, et al. Reproductive factors, smoking, and the risk for rheumatoid arthritis. Epidemiology (1990) 1:285-91. doi:10.1097/00001648-199007000-00005

77. Cerhan JR, Saag KG, Criswell LA, Merlino LA, Mikuls TR. Blood transfusion, alcohol use, and anthropometric risk factors for rheumatoid arthritis in older women. J Rheumatol (2002) 29:246-54.

78. Pedersen M, Jacobsen S, Klarlund M, Pedersen BV, Wiik A, Wohlfahrt J, et al. Environmental risk factors differ between rheumatoid arthritis with and without auto-antibodies against cyclic citrullinated peptides. Arthritis Res Ther (2006) 8:R133. doi:10.1186/ar2022

79. Crowson CS, Matteson EL, Davis JM III, Gabriel SE. Contribution of obesity to the rise in incidence of rheumatoid arthritis. Arthritis Care Res (2013) 65:71-7. doi:10.1002/acr.21660

80. Wesley A, Bengtsson C, Elkan AC, Klareskog L, Alfredsson L, Wedrén S, et al. Association between body mass index and anti-citrullinated protein antibodypositive and anti-citrullinated protein antibody-negative rheumatoid arthritis: results from a population-based case-control study. Arthritis Care Res (Hoboken) (2013) 65:107-12. doi:10.1002/acr.21749

81. Lahiri M, Luben RN, Morgan C, Bunn DK, Marshall T, Lunt M, et al. Using lifestyle factors to identify individuals at higher risk of inflammatory polyarthritis (results from the European Prospective Investigation of CancerNorfolk and the Norfolk Arthritis Register - the EPIC-2-NOAR Study). Ann Rheum Dis (2014) 73:219-26. doi:10.1136/annrheumdis-2012-202481

82. Lu B, Hiraki LT, Sparks JA, Malspeis S, Chen CY, Awosogba JA, et al. Being overweight or obese and risk of developing rheumatoid arthritis among women: a prospective cohort study. Ann Rheum Dis (2014) 3(11):1914-22. doi:10.1136/annrheumdis-2014-205459

83. Ajeganova S, Andersson ML, Hafström I; BARFOT Study Group. Association of obesity with worse disease severity in rheumatoid arthritis as well as with comorbidities: a long-term followup from disease onset. Arthritis Care Res (2013) 65:78-87. doi:10.1002/acr.21710

84. Stavropoulos-Kalinoglou A, Metsios GS, Panoulas VF, Nevill AM, Jamurtas AZ, Koutedakis $\mathrm{Y}$, et al. Underweight and obese states both associate with worse disease activity and physical function in patients with established rheumatoid arthritis. Clin Rheumatol (2009) 28:439-44. doi:10.1007/s10067-0081073-z

85. Jawaheer D, Olsen J, Lahiff M, Forsberg S, Lahteenmaki J, da Silveira IG, et al. Gender, body mass index and rheumatoid arthritis disease activity: results from the QUEST-RA study. Clin Exp Rheumatol (2010) 28:454-61. doi:10.1002/acr.21978
86. Heimans L, van den Broek M, le Cessie S, Siegerink B, Riyazi N, Han KH, et al. Association of high body mass index with decreased treatment response to combination therapy in recent-onset rheumatoid arthritis patients. Arthritis Care Res (2013) 65:1235-42. doi:10.1002/acr.21978

87. Gremese E, Fedele AL, Gigante MR, Tolusso B, Carbonella A, Bosello SL, et al. The body mass index: a determinant of remission in early rheumatoid arthritis. Ann Rheum Dis (2013) 72:A113. doi:10.1136/annrheumdis-2013-eular.383

88. Visser M, Langlois J, Guralnik JM, Cauley JA, Kronmal RA, Robbins J, et al. High body fatness, but not low fat-free mass, predicts disability in older men and women: the Cardiovascular Health Study. Am J Clin Nutr (1998) 68:584-90.

89. Hassan MK, Joshi AV, Madhavan SS, Amonkar MM. Obesity and health-related quality of life: a cross-sectional analysis of the US population. Int J Obes Relat Metab Disord (2003) 27:1227-32. doi:10.1038/sj.ijo.0802396

90. Caplan L, Davis LA, Bright CM, Kerr GS, Lazaro DM, Khan NA, et al. Body mass index and the rheumatoid arthritis swollen joint count: an observational study. Arthritis Care Res (2013) 65:101-6. doi:10.1002/acr.21734

91. Westhoff G, Rau R, Zink A. Radiographic joint damage in early rheumatoid arthritis is highly dependent on body mass index. Arthritis Rheum (2007) 56:3575-82. doi:10.1002/art.23033

92. van der Helm-van Mil AH, van der Kooij SM, Allaart CF, Toes RE, Huizinga TW. A high body mass index has a protective effect on the amount of joint destruction in small joints in early rheumatoid arthritis. Ann Rheum Dis (2008) 67:769-74. doi:10.1136/ard.2007.078832

93. Kaufmann J, Kielstein V, Kilian S, Stein G, Hein G. Relation between body mass index and radiological progression in patients with rheumatoid arthritis. J Rheumatol (2003) 30:2350-5.

94. Baker JF, Ostergaard M, George M, Shults J, Emery P, Baker DG, et al. Greater body mass independently predicts less radiographic progression on X-ray and MRI over 1-2 years. Ann Rheum Dis (2014) 73(11):1923-8. doi:10.1136/ annrheumdis-2014-205544

95. Giles JT, Allison M, Bingham CO III, Scott WM Jr, Bathon JM. Adiponectin is a mediator of the inverse association of adiposity with radiographic damage in rheumatoid arthritis. Arthritis Rheum (2009) 61:1248-56. doi:10.1002/art 24789

96. Ferraccioli G, Trotta F, Punzi L, Ferri C, Sarzi-Puttini P, Bambara LM, et al. Body weight and response to biologics in RA and spondyloarthritides. Obesity reduces the rate of remission-response. The GISEA registry. Arthritis Rheum (2010) 62(Suppl 10):297.

97. Smolen JS, Szumski S, Koening AS, Jones TV. Impact of body mass index on response to etanercept therapy in subjects with moderately active rheumatoid arthritis in the PRESERVE trial. Arthritis Rheum (2011) 63(Suppl):S154.

98. Sandberg ME, Bengtsson C, Källberg H, Wesley A, Klareskog L, Alfredsson $\mathrm{L}$, et al. Overweight decreases the chance of achieving good response and low disease activity in early rheumatoid arthritis. Ann Rheum Dis (2014) 73(11):2029-33. doi:10.1136/annrheumdis-2013-205094

99. Gremese E, Ferraccioli G. The metabolic syndrome: the crossroads between rheumatoid arthritis and cardiovascular risk. Autoimmun Rev (2011) 10:582-9. doi:10.1016/j.autrev.2011.04.018

100. Wojtal KA, Rogler G, Scharl M, Biedermann L, Frei P, Fried M, et al. Fc gamma receptor CD64 modulates the inhibitory activity of infliximab. PLoS One (2012) 7:e43361. doi:10.1371/journal.pone.0043361

101. Palming J, Gabrielsson BG, Jennische E, Smith U, Carlsson B, Carlsson LM, et al. Plasma cells and $\mathrm{Fc}$ receptors in human adipose tissue-lipogenic and antiinflammatory effects of immunoglobulins on adipocytes. Biochem Biophys Res Commun (2006) 343:43-8. doi:10.1016/j.bbrc.2006.02.114

102. Gremese E, Bernardi S, Bonazza S, Nowik M, Peluso G, Massara A, et al. Body weight, gender and response to TNF- $\alpha$ blockers in axial spondyloarthritis. Rheumatology (2014) 53:875-81. doi:10.1093/rheumatology/ket433

103. Armstrong AW, Harskamp CT, Armstrong EJ. The association between psoriasis and obesity: a systematic review and meta-analysis of observational studies. Nutr Diabetes (2012) 2:e54. doi:10.1097/HJH.0b013e32835bcce1

104. Bhole VM, Choi HK, Burns LC, Vera Kellet C, Lacaille DV, Gladman DD, et al. Differences in body mass index among individuals with PsA, psoriasis, RA and the general population. Rheumatology (2012) 51:552-6. doi:10.1093/ rheumatology/ker349

105. Love TJ, Zhu Y, Zhang Y, Wall-Burns L, Ogdie A, Gelfand JM, et al. Obesity and the risk of psoriatic arthritis: a population-based study. Ann Rheum Dis (2012) 71:1273-7. doi:10.1136/annrheumdis-2012-201299 
106. Di Minno MN, Peluso R, Iervolino S, Lupoli R, Russolillo A, Scarpa R, et al. Obesity and the prediction of minimal disease activity: a prospective study in psoriatic arthritis. Arthritis Care Res (2013) 65:141-7. doi:10.1002/acr.21711

107. Eder L, Thavaneswaran A, Chandran V, Cook RJ, Gladman DD. Obesity is associated with a lower probability of achieving sustained minimal disease activity state among patients with psoriatic arthritis. Ann Rheum Dis (2014). doi:10.1136/annrheumdis-2013-204448

108. Naldi L, Conti A, Cazzaniga S, Patrizi A, Pazzaglia M, Lanzoni A, et al. Diet and physical exercise in psoriasis: a randomized controlled trial. Br J Dermatol (2014) 170:634-42. doi:10.1111/bjd.12735

109. Di Minno MN, Peluso R, Iervolino S, Russolillo A, Lupoli R, Scarpa R, et al. Weight loss and achievement of minimal disease activity in patients with psoriatic arthritis starting treatment with tumour necrosis factor $\alpha$ blockers. Ann Rheum Dis (2014) 73:1157-62. doi:10.1136/annrheumdis-2012-202812

110. Jensen P, Zachariae C, Christensen R, Geiker NR, Schaadt BK, Stender S, et al. Effect of weight loss on the cardiovascular risk profile of obese patients with psoriasis. Acta Derm Venereol (2014) 94(6):691-4. doi:10.2340/00015555-1824

111. Katz P, Gregorich S, Yazdany J, Trupin L, Julian L, Yelin E, et al. Obesity and its measurement in a community-based sample of women with systemic lupus erythematosus. Arthritis Care Res (2011) 63:261-8. doi:10.1002/acr.20343

112. Petri M. Detection of coronary artery disease and the role of traditional risk factors in the Hopkins lupus cohort. Lupus (2000) 9:170-5. doi:10.1191/ 096120300678828226

113. Oeser A, Chung CP, Asanuma Y, Avalos I, Stein CM. Obesity is an independent contributor to functional capacity and inflammation in systemic lupus erythematosus. Arthritis Rheum (2005) 52:3651-9. doi:10.1002/art.21400

114. Chaiamnuay S, Bertoli AM, Fernandez M; LUMINA Study Group. The impact of increased body mass index on systemic lupus erythematosus: data from LUMINA, a multiethnic cohort (LUMINA XLVI). J Clin Rheumatol (2007) 13:128-33. doi:10.1097/RHU.0b013e3180645865

115. Karadag O, Calguneri M, Atalar E, Yavuz B, Akdogan A, Kalyoncu U, et al. Novel cardiovascular risk factors and cardiac event predictors in female inactive systemic lupus erythematosus patients. Clin Rheumatol (2007) 26:695-9. doi:10.1007/s10067-006-0376-1

116. Lozovoy MA, Simão AN, Hohmann MS, Simão TN, Barbosa DS, Morimoto HK, et al. Inflammatory biomarkers and oxidative stress measurements in patients with systemic lupus erythematosus with or without metabolic syndrome. Lupus (2011) 20:1356-64. doi:10.1177/0961203311411348

117. Almehed K, Carlsten H, Forsblad-d'Elia H. Health-related quality of life in systemic lupus erythematosus and its association with disease and work disability. Scand J Rheumatol (2010) 39:58-62. doi:10.3109/03009740903124408

118. Rizk A, Gheita TA, Nassef S, Abdallah A. The impact of obesity in systemic lupus erythematosus on disease parameters, quality of life, functional capacity and the risk of atherosclerosis. Int J Rheum Dis (2012) 15:261-7. doi:10.1111/j.1756-185X.2011.01698.x

119. Mok CC, Tang SS, To CH, Petri M. Incidence and risk factors of thromboembolism in systemic lupus erythematosus: a comparison of three ethnic groups. Arthritis Rheum (2005) 52:2774-82. doi:10.1002/art.21224

120. Chaiamnuay S, Bertoli AM, Roseman JM, McGwin G, Apte M, Durán S, et al. African-American and Hispanic ethnicities, renal involvement and obesity predispose to hypertension in systemic lupus erythematosus: results from LUMINA, a multiethnic cohort (LUMINAXLV). Ann Rheum Dis (2007) 66:618-22. doi:10.1136/ard.2006.059311

121. Cervera R, Khamashta MA, Font J, Sebastiani GD, Gil A, Lavilla P, et al. Morbidity and mortality in systemic lupus erythematosus during a 10-year period: a comparison of early and late manifestations in a cohort of 1,000 patients. European Working Party on Systemic Lupus Erythematosus. Medicine (2003) 82:299-308. doi:10.1097/01.md.0000091181.93122.55

122. Urowitz MB, Bookman AA, Koehler BE, Gordon DA, Smythe HA, Ogryzlo MA. The bimodal mortality pattern of systemic lupus erythematosus. Am J Med (1976) 60:221-5. doi:10.1016/0002-9343(76)90431-9

123. Ngian GS, Sahhar J, Proudman SM, Stevens W, Wicks IP, Van Doornum S. Prevalence of coronary heart disease and cardiovascular risk factors in a national cross-sectional cohort study of systemic sclerosis. Ann Rheum Dis (2012) 71:1980-3. doi:10.1136/annrheumdis-2011-201176

124. Caramaschi P, Biasi D, Caimmi C, Barausse G, Gatti D, Ferrari M, et al. Relationship between body composition and both cardiovascular risk factors and lung function in systemic sclerosis. Clin Rheumatol (2014) 33:77-82. doi:10.1007/s10067-013-2388-y

125. Rossi AP, Watson NL, Newman AB, Harris TB, Kritchevsky SB, Bauer DC, et al. Effects of body composition and adipose tissue distribution on respiratory function in elderly men and women: the health, aging, and body composition study. J Gerontol A Biol Sci Med Sci (2011) 66:801-8. doi:10.1093/gerona/glr058

126. Marighela TF, Genaro Pde S, Pinheiro MM, Szejnfeld VL, Kayser C. Risk factors for body composition abnormalities in systemic sclerosis. Clin Rheumatol (2013) 32:1037-44. doi:10.1007/s10067-013-2235-1

127. Assassi S, Del Junco D, Sutter K, McNearney TA, Reveille JD, Karnavas A, et al. Clinical and genetic factors predictive of mortality in early systemic sclerosis. Arthritis Rheum (2009) 61:1403-11. doi:10.1002/art.24734

128. Lendrem D, Mitchell S, McMeekin P, Bowman S, Price E, Pease CT, et al. Healthrelated utility values of patients with primary Sjögren's syndrome and its predictors. Ann Rheum Dis (2014) 73:1362-8. doi:10.1136/annrheumdis-2012202863

Conflict of Interest Statement: The authors declare that the research was conducted in the absence of any commercial or financial relationships that could be construed as a potential conflict of interest.

Received: 22 August 2014; accepted: 27 October 2014; published online: 11 November 2014.

Citation: Gremese E, Tolusso B, Gigante MR and Ferraccioli G (2014) Obesity as a risk and severity factor in rheumatic diseases (autoimmune chronic inflammatory diseases). Front. Immunol. 5:576. doi: 10.3389/fimmu.2014.00576

This article was submitted to Inflammation, a section of the journal Frontiers in Immunology.

Copyright (C) 2014 Gremese, Tolusso, Gigante and Ferraccioli. This is an open-access article distributed under the terms of the Creative Commons Attribution License (CC BY). The use, distribution or reproduction in other forums is permitted, provided the original author(s) or licensor are credited and that the original publication in this journal is cited, in accordance with accepted academic practice. No use, distribution or reproduction is permitted which does not comply with these terms. 